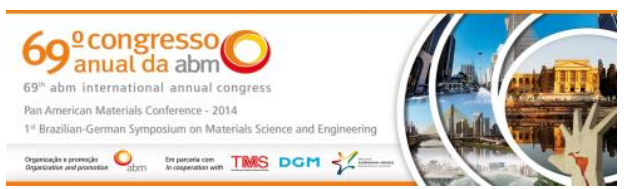

Tema: Iniciação Científico-tecnológica

\title{
INFLUÊNCIA DO APORTE TÉRMICO DE SOLDAGEM NO CRESCIMENTO DE TRINCA POR FADIGA EM JUNTAS SOLDADAS DE DOIS AÇOS INOXIDÁVEIS FERRÍTICOS*
}

\author{
Túlio César Nogueira ${ }^{1}$ \\ Vitor Pereira Alves ${ }^{1}$ \\ Leonardo Barbosa Godefroid² \\ Geraldo Lúcio de Faria² \\ Paulo José Modenesi ${ }^{3}$
}

\section{Resumo}

Este trabalho teve como objetivo estudar a resistência ao crescimento de trinca por fadiga de juntas soldadas de aços inoxidáveis ferríticos do tipo UNS S40910 e UNS S41003, com entalhe na ZTA. Os ensaios de fadiga foram realizados em juntas soldadas com alta e baixa energia de soldagem realizadas pelo processo GMAW, tendo como metal de adição o consumível austenítico ER $308 \mathrm{LSi}$, e em amostras do metal de base de ambos os aços. Os ensaios foram realizados sob controle de carga com a amplitude de carregamento constante, e razão $\mathrm{R}$ entre tensões de 0,1. Os resultados foram obtidos na forma de curvas (da/dN) vs. $\Delta K$, com caracterização das regiões I e II do crescimento de trinca por fadiga. Analisou-se também os aspectos microestruturais e fratográficos por intermédio de microscopia ótica e microscopia eletrônica de varredura, respectivamente, como suporte para se justificar o comportamento sob fadiga das amostras. Embora os dois aços tenham comportamento distinto, pode-se concluir que as juntas soldadas não apresentaram efeito do aporte térmico, não sendo influenciados pelas alterações microestruturais existentes na ZTA.

Palavras-chave: Crescimento de trincas por fadiga; Juntas soldadas; Aços inoxidáveis ferríticos.

\section{INFLUENCE OF WELDING ENERGY ON THE FATIGUE CRACK GROWTH IN WELDED JOINTS OF TWO FERRTIC STAINLESSSTEELS}

\section{Abstract}

This work aimed to study the fatigue crack growth resistance of welded joints of two ferritic stainless steels (grades S40910 and S41003), with notch in the heat affected zone (HAZ). The fatigue tests were performed on welded joints produced by Gas Metal Arc Welding (GMAW), and also on the base metals. Welding was performed in 2 energy levels, using an AWS SFA 5.9 E308 LSi wire. Fatigue tests were performed under load control and R ratio = 0.1 . The results were obtained using the methodology of fracture mechanics (da/dN vs. $\Delta \mathrm{K}$ curves), with characterization of regions I and II of the sigmoidal fatigue crack growth curve. Microstructures and fractures were also observed through optical microscopy and scanning electron microscopy, respectively, as a support to justify the fatigue behavior of the specimens. Although the two steels have distinct behavior, it was possible to conclude that the welded joints showed no effect of heat supply, not being influenced by microstructural changes in the HAZ.

Keywords: Fatigue crack growth; Welded joints; Ferritic stainless steels.

1 Aluno de Engenharia Metalúrgica, DEMET, Escola de Minas, Universidade Federal de Ouro Preto, Ouro Preto, MG, Brasil.

2 Engenheiro Metalúrgico, M.Sc., D.Sc., DEMET, Escola de Minas, Universidade Federal de Ouro Preto, Ouro Preto, MG, Brasil.

3 Engenheiro Metalúrgico, M.Sc., D.Sc., DEMET, Escola de Engenharia, Universidade Federal de Minas Gerais, Belo Horizonte, MG, Brasil.

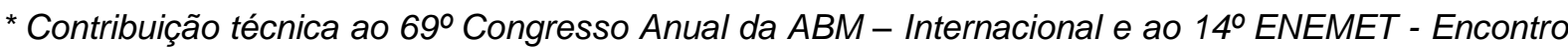
Nacional de Estudantes de Engenharia Metalúrgica, de Materiais e de Minas, 21 a 25 de julho de 2014, São Paulo, SP, Brasil.
} 


\section{INTRODUÇÃO}

A produção anual de aços inoxidáveis no mundo em 2012 atingiu cerca de 35,4 milhões de toneladas. A participação do Brasil foi de aproximadamente 390 mil toneladas, com consumo per capita tímido de $1,96 \mathrm{~kg} / \mathrm{habitante}$ por ano. Ainda, considerando a produção mundial em $2012,53 \%$ do total foram da série $300,20 \%$ da série $200,25 \%$ da série 400 e $2 \%$ do tipo duplex [1]. A série 300 , constituída pelos aços austeníticos, utiliza o elemento níquel na sua composição, variando de 7 a $20 \%$ em peso, cujo preço no mercado é de cerca de US $\$ 16,00 / \mathrm{kg}$ [2]. Isto faz com que as ligas da série 300 sejam dispendiosas, constituindo uma barreira para a expansão do mercado de aços inoxidáveis. Desta forma, há uma tendência mundial em substituir os aços da série 300 pelos aços que não utilizam o níquel ou que 0 tenham em menores teores. Uma das estimativas de mercado aponta que em 2020 os aços da série 400 aumentarão para $37 \%$, enquanto os da série 300 sofrerão uma queda para $53 \%$, dentro de um cenário de produção mundial que alcançará 45 milhões de toneladas/ano [3]. Isto parece bastante promissor particularmente para os aços ferríticos que compõem a série 400 ao lado dos aços martensíticos. Contudo, a aplicação dos aços inoxidáveis ferríticos em substituição aos austeníticos não é uma tarefa fácil devido às diferenças de propriedades destes materiais, sendo as características mecânicas uma destas variáveis relevantes. Os aços inoxidáveis ferríticos apresentam menor ductilidade em relação aos aços austeníticos, suscetibilidade a fenômenos de fragilidade, sensibilidade ao entalhe (maior propensão a apresentar comportamento frágil, particularmente na presença de entalhes) e soldabilidade inferior [4-6]. Como consequência destes fatores, muitas aplicações são limitadas a espessuras reduzidas, abaixo de $3 \mathrm{~mm}$ [7], e muitos esforços têm sido realizados para viabilizar a aplicação destes materiais em estruturas mais pesadas.

Atualmente, a aplicação dos aços inoxidáveis ferríticos está consolidada em sistemas de exaustão automotiva, em bens de capital nas indústrias de celulose, sucro-alcooleira e cítrica, trocadores de calor, caçambas de mineração e petroquímica e contêineres marítimos $[7,8]$. Em diversas aplicações, os aços inoxidáveis ferríticos, sobretudo as ligas com menor teor de cromo, podem substituir o aço carbono com algumas vantagens: dispensar pinturas contra corrosão ou a construção de estruturas mais leves, reduzindo a espessura de compensação para corrosão [9].

Considerando o contexto apresentado, o presente trabalho visa formar subsídios técnicos para estudos de diversificação do uso dos aços inoxidáveis ferríticos, sobretudo em estruturas soldadas e com espessuras acima daquelas normalmente utilizadas nestas ligas. A outra razão para este estudo é o fato dos modernos projetos mecânicos utilizarem cálculos cada vez mais precisos, que permitem a redução dos fatores de segurança, e desta forma, resultam em menor custo de fabricação devido à redução da quantidade de material utilizado. Este processo requer melhor conhecimento das propriedades dos materiais aplicados, assim como as propriedades oriundas dos processos envolvidos no processamento destes materiais.

Particularmente no caso da soldagem, uma preocupação técnica é o possível aumento do tamanho de grão da zona termicamente afetada (ZTA).

Oliveira e Faria [10] destacam que uma das maneiras mais utilizadas para controlar este tamanho de grão, além dos elementos estabilizadores, é por intermédio da energia de soldagem. Quanto menor o seu valor, menor é o tamanho de grão

\footnotetext{
* Contribuição técnica ao $69^{\circ}$ Congresso Anual da ABM - Internacional e ao 14ํㅡㄹ ENEMET - Encontro Nacional de Estudantes de Engenharia Metalúrgica, de Materiais e de Minas, 21 a 25 de julho de 2014, São Paulo, SP, Brasil.
} 


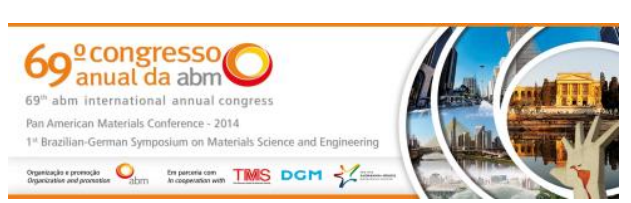

resultante. Isto se deve ao menor aporte térmico cedido à peça a ser soldada. Portanto, é aconselhável soldar com uma menor energia de soldagem possível para obtenção de grãos menores e uma ZTA com tamanho de grão próximo a do metal base.

Este trabalho consistiu na caracterização da resistência ao crescimento de trinca por fadiga de juntas soldadas de dois aços inoxidáveis ferríticos, com dois diferentes aportes térmicos, com entalhe posicionado na zona termicamente afetada. Trata-se de uma complementação da pesquisa realizada por Hibino et al. [11,12], onde se caracterizou a resistência mecânica por tração, dureza e impacto das juntas soldadas.

\section{MATERIAIS E MÉTODOS}

Os aços inoxidáveis ferríticos utilizados neste estudo são classificados como UNS S40910 e UNS S41003, conforme a norma ASTM A240 [13]. Estes aços pertencem à categoria de ligas de baixo custo com teores reduzidos de carbono e cromo, sendo este último elemento limitado a aproximadamente $11 \%$. Os aços foram obtidos em linha de produção em escala industrial com espessura de $6,5 \mathrm{~mm}$, sendo o aço S40910 laminado a quente e decapado e o aço S41003 laminado a quente, recozido em forno do tipo caixa e decapado.

As análises químicas foram realizadas $[11,12]$ por intermédio de espectrometria por fluorescência de raios-X (XRF), utilizando o equipamento ARL 9900 Series da Thermo Scientific.

A soldagem das amostras de chapa foi realizada $[11,12]$ em junta meio-V, mostrada esquematicamente na Figura 1 pelo processo GMAW em único passe na direção de laminação das chapas. O metal de adição utilizado foi o arame maciço AWS A 5.9 ER 308 LSi de 1,2mm de diâmetro e a proteção foi com uma mistura de argônio com $2 \%$ de oxigênio. Os parâmetros de soldagem utilizados estão descritos na Tabela 1, sendo aqui classificados como Alta Energia (AE) e Baixa Energia (BE).

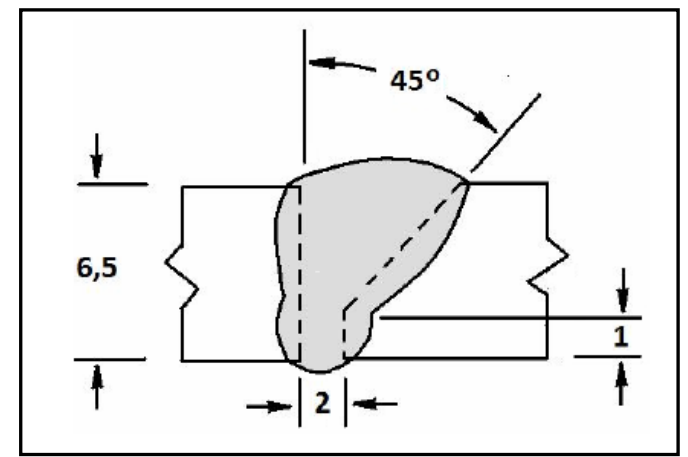

Figura 1. Configuração da junta meio-V [11]

Tabela 1. Parâmetros de soldagem utilizados no estudo [11]

\begin{tabular}{cccccc}
\hline $\begin{array}{c}\text { Corrente } \\
(\mathrm{A})\end{array}$ & $\begin{array}{c}\text { Tensão } \\
(\mathrm{V})\end{array}$ & $\begin{array}{c}\text { Velocidade de } \\
\text { soldagem }(\mathrm{cm} / \mathrm{min})\end{array}$ & $\begin{array}{c}\text { Velocidade do arame } \\
(\mathrm{m} / \mathrm{min})\end{array}$ & $\begin{array}{c}\text { Energia } \\
(\mathrm{kJ} / \mathrm{mm})\end{array}$ \\
\hline $\mathrm{BE}$ & 210 & 26 & 30 & 7 & 1,1 \\
\hline $\mathrm{AE}$ & 260 & 28,5 & 25 & 10 & 1,8 \\
\hline
\end{tabular}

Após a confecção das juntas soldadas, a retirada dos corpos de prova para os ensaios de fadiga seguiu a configuração apresentada na Figura 2(a) e o entalhe foi posicionado na ZTA no lado reto do chanfro. Após os ensaios, amostras foram

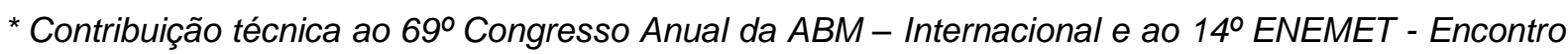
Nacional de Estudantes de Engenharia Metalúrgica, de Materiais e de Minas, 21 a 25 de julho de 2014, São Paulo, SP, Brasil. 


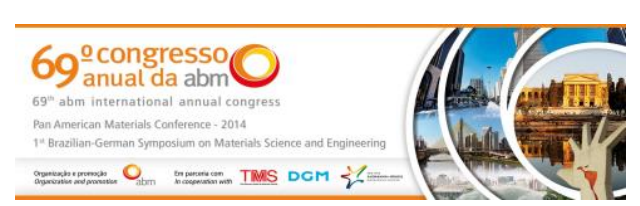

Com relação à composição química, a amostra do aço estabilizado $\mathbf{S 4 0 9 1 0}$ apresentou relação entre elementos $\mathrm{Ti}$ e intersticiais $\mathrm{C}+\mathrm{N}$ acima do mínimo especificado pela norma ASTM A240 [13] para esta liga, que é de seis, indicando estabilização adequada da ferrita. Embora a estabilidade da ferrita seja definida para KFF > 13,5 nos aços inoxidáveis de baixo teor de cromo, o aço S40910 estudado, supostamente ferrítico em todas as faixas de temperatura, apresentou um valor levemente menor, igual a 13,25. Por outro lado, o valor de $\Delta$ Ti para o aço $\$ 40910$ foi positivo, indicando que há Ti em solução sólida e está em consonância com a relação $\mathrm{Ti} /(\mathrm{C}+\mathrm{N})$. Já o aço $\$ 41003$ apresentou $\mathrm{KFF}$ igual a 11,18, isto é, maior predominância de elementos austenitizantes do que o aço S40910. Isto resulta na possibilidade de formação de austenita durante aquecimento a alta temperatura e, desta forma, de martensita no resfriamento.

\subsection{Avaliação Microestrutural}

A Figura 3(a,b) mostra as microestruturas dos aços estudados no estado de entrega. O aço S40910 apresentou uma distribuição de grãos equiaxiais de ferrita, com tamanho de grão médio aproximadamente igual a $45 \mu \mathrm{m}$. Este valor mostra que a microestrutura deste aço é mais grosseira do que a encontrada em material típico, laminado a frio e recozido, com espessura de $1,5 \mathrm{~mm}$, que apresenta tamanho de grão médio de $30 \mu \mathrm{m}$ [18]. Por outro lado, o aço S41003 apresentou uma distribuição de grãos alongados e heterogêneos de ferrita, com tamanho de grão médio aproximadamente igual a $14 \mu \mathrm{m}$. Ambos os aços apresentaram uma fina distribuição de precipitados (carbonetos) dentro dos grãos e nos contornos de grãos, sendo que o aço S40910 ainda mostrou a presença de TiN em sua microestrutura (resultados não mostrados na Figura 3, mas observados com maior ampliação [11,12]). Todos estes resultados encontram-se de acordo com a composição química dos aços, e as diferenças microestruturais estão relacionados com os procedimentos de fabricação dos dois aços.

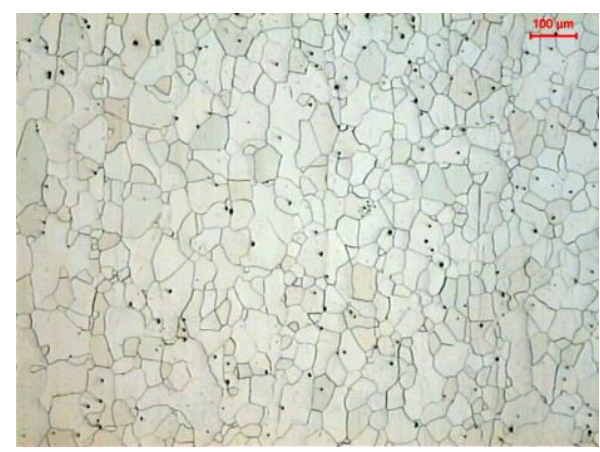

(a) S40910.

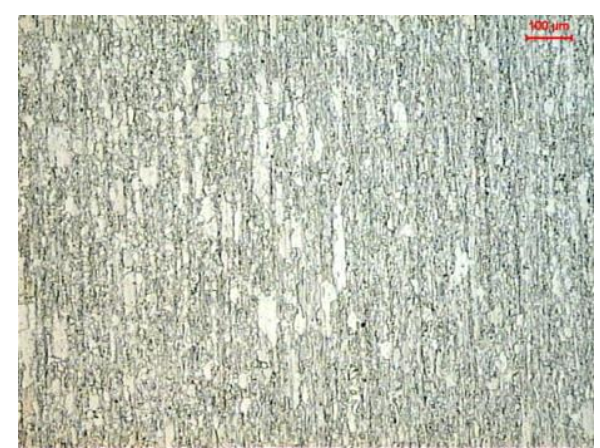

(b) S41003.

Figura 3. Microestrutura dos aços no estado de entrega, $\mathrm{MO}$, ataque Villela.

A Figura 4(a,b) mostra as microestruturas da junta soldada do aço S40910, respectivamente para baixa energia $(B E)$ e alta energia $(A E)$, na região de granulação grosseira da ZTA. Como neste caso a composição química do aço indica estabilidade da ferrita, a microestrutura apresentou somente esta fase durante a soldagem. Por outro lado, como não existe mecanismo de ancoramento para crescimento de grão (uma única fase presente), ocorreu crescimento expressivo de tamanho de grão: a junta BE apresentou um tamanho de grão aproximadamente de $186 \mu \mathrm{m}$, enquanto a junta $\mathrm{AE}$ apresentou um tamanho de grão aproximadamente de $285 \mu \mathrm{m}$. Observou-se também um aumento da espessura da ZTA com o aumento do

* Contribuição técnica ao 69 Congresso Anual da ABM - Internacional e ao 14ํㅡㄹ ENEMET - Encontro Nacional de Estudantes de Engenharia Metalúrgica, de Materiais e de Minas, 21 a 25 de julho de 2014, São Paulo, SP, Brasil. 
aporte térmico de soldagem. Uma maneira de minimizar estes efeitos seria a diminuição do aporte térmico [10,19].

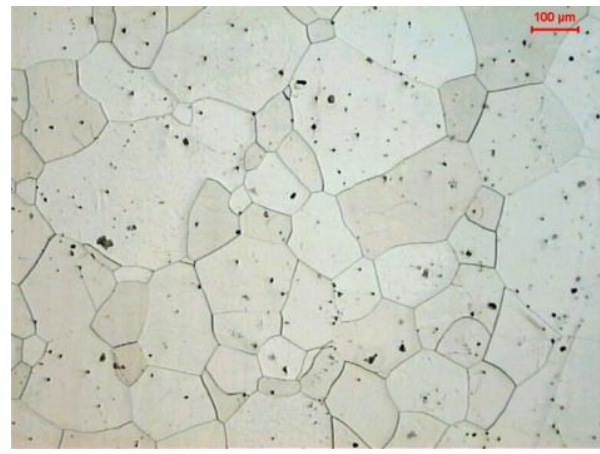

(a) S40910 BE.

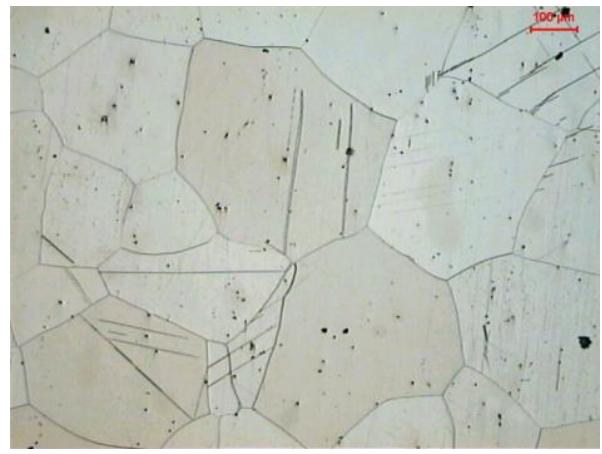

(b) S40910 AE.

Figura 4. Microestrutura da junta soldada (ZTA) do aço S40910, MO, ataque Villela.

A Figura 5 mostra as microestruturas da junta soldada do aço S41003, respectivamente para baixa energia $(B E)$ e alta energia $(A E)$, na região de granulação grosseira da ZTA. Como neste caso há ausência de elementos estabilizantes da ferrita, existe condição para formação de martensita durante o resfriamento subsequente à soldagem. Pode-se então perceber para ambas situações a formação de grãos de ferrita circundados por martensita. Na ZTA deste aço observou-se a formação de duas regiões distintas, de forma similar à relatada por Du Toit e colaboradores [20] em um aço 1.4003 (que é um aço similar ao S41003), para o qual indicam a existência de uma região de alta temperatura (ZTAAT) e outra de baixa temperatura (ZTA-BT). O tamanho de grão ferrítico ficou em faixas semelhantes ao caso do aço S40910. Observou-se novamente um aumento da espessura da ZTA com o aumento do aporte térmico de soldagem.

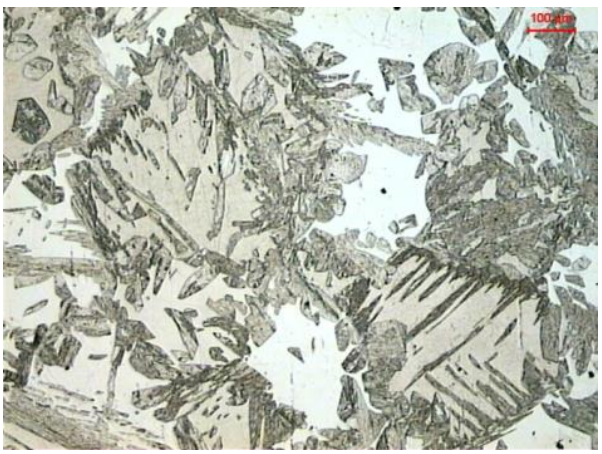

(a) S41003 BE.

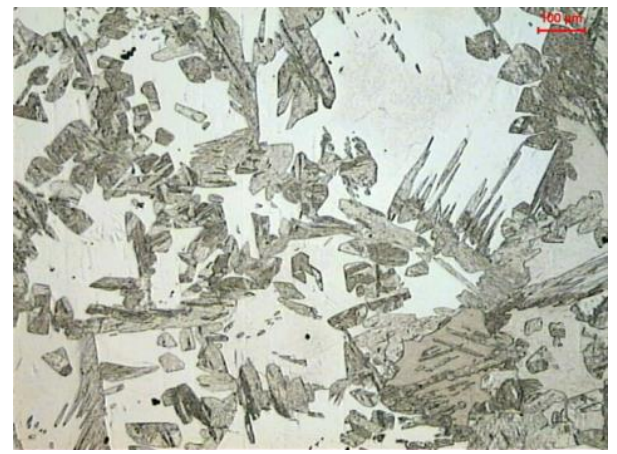

(b) S41003 AE.

Figura 5. Microestrutura da junta soldada (ZTA-AT) do aço S41003, MO, ataque Villela.

\subsection{Crescimento de Trinca por Fadiga}

A Figura 6 mostra as curvas sigmoidais de crescimento de trinca por fadiga dos dois aços inoxidáveis ferríticos, destacando-se as regiões I e II do tradicional gráfico $d a / d N \times \Delta K$. Pode-se observar uma diferença significativa de comportamento entre os aços no início do trincamento (região de cisalhamento de planos cristalográficos), com valores de $\Delta K_{T H}$ de 12,8 e $10,8 \mathrm{MPa} \sqrt{\mathrm{m}}$, respectivamente para os aços $\mathrm{S} 40910$ e S41003. Esta diferença de comportamento é creditada ao fenômeno de fechamento de trinca por rugosidade/tortuosidade, que forneceu valores de $K_{C L} / K_{\max }$ de 0,76 e 0,41 para cada um dos aços em questão na região do limiar $\Delta K_{T H}$. Nesta

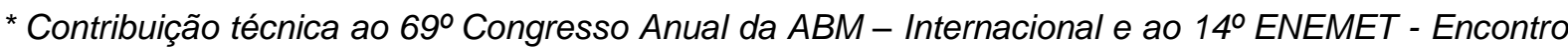
Nacional de Estudantes de Engenharia Metalúrgica, de Materiais e de Minas, 21 a 25 de julho de 2014, São Paulo, SP, Brasil.
} 


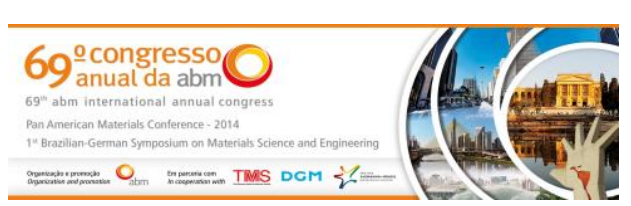

região, o tamanho de grão e o limite de escoamento por tração do material exercem um efeito competitivo e significativo [21,22]. Por outro lado, na região de relação linear entre $d a / d N$ e $\Delta K$ (região de formação de estrias de fadiga), não foi notada diferença de comportamento entre os aços estudados. Novamente, o fechamento de trinca pode explicar este comportamento, uma vez que para ambos materiais a relação $K_{C L} / K_{\max }$ tende para o valor constante de 0,30 , independente do valor de $\Delta K$.

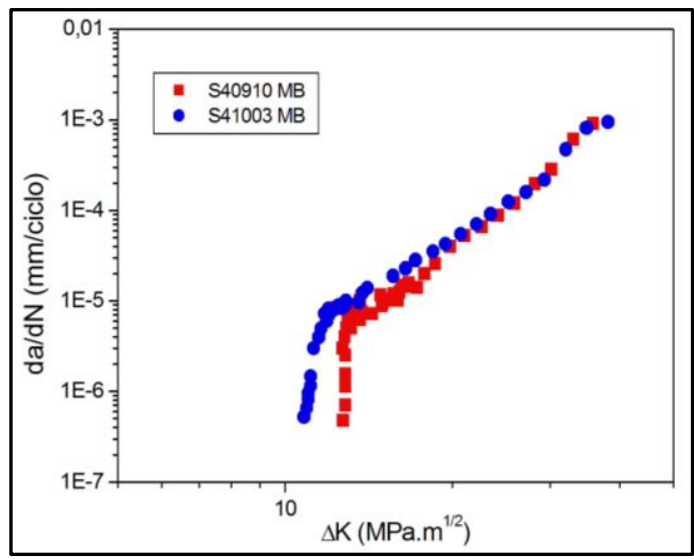

Figura 6. Curvas de crescimento de trinca por fadiga dos aços S40910 e S41003.

A Figura 7(a,b) mostra o efeito do aporte térmico de soldagem no crescimento de trinca por fadiga das duas juntas soldadas. Com relação ao aço S40910, pode-se observar que existe uma variação significativa de comportamento na região I de crescimento de trinca, quando se compara o metal base com a junta soldada. Este efeito deixa de existir na região II de crescimento de trinca. Estes resultados podem ser melhor visualizados na Figura $8(a, b, c)$, quando se apresenta a variação de $\Delta K_{T H}$ e das constantes $C$ e $m$ da equação de Paris com a energia de soldagem. Por outro lado, para o aço S41003 não se verifica nenhum efeito significativo nas duas regiões das curvas sigmoidais, entre o metal base e as juntas soldadas, independentemente das variações microestruturais observadas. Estes resultados também são mostrados na Figura 8(a,b,c).

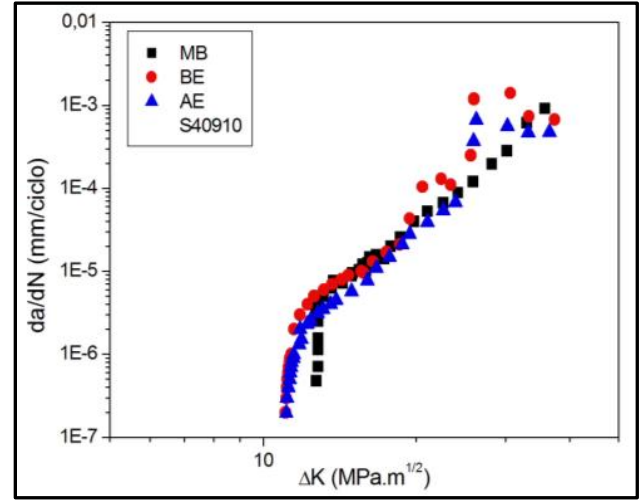

(a) S40910.

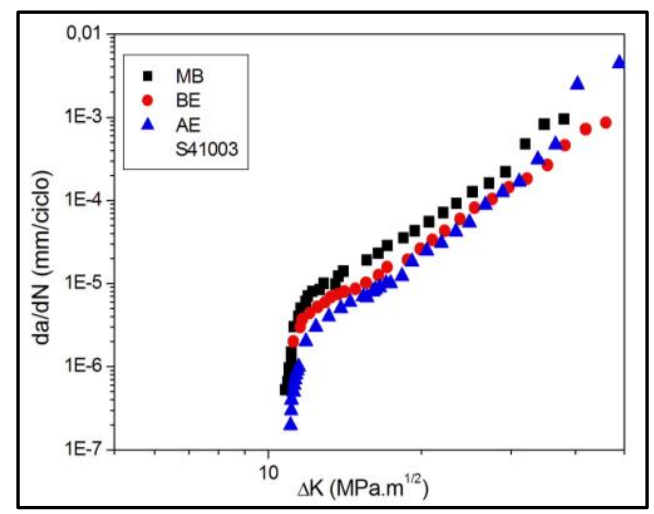

(b) S41003.

Figura 7. Efeito do aporte térmico de soldagem nas curvas de crescimento de trinca por fadiga das juntas soldadas dos aços S40910 e S41003.

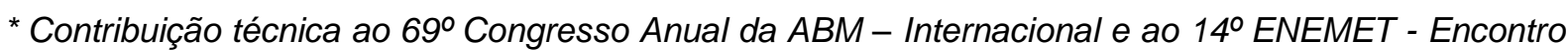
Nacional de Estudantes de Engenharia Metalúrgica, de Materiais e de Minas, 21 a 25 de julho de 2014, São Paulo, SP, Brasil. 


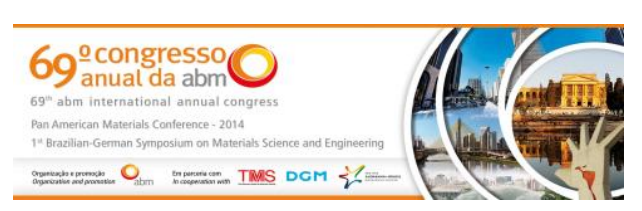

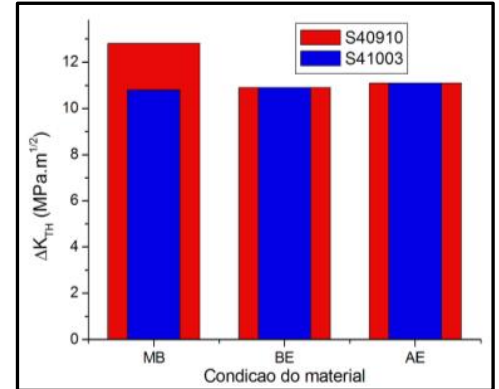

(a)

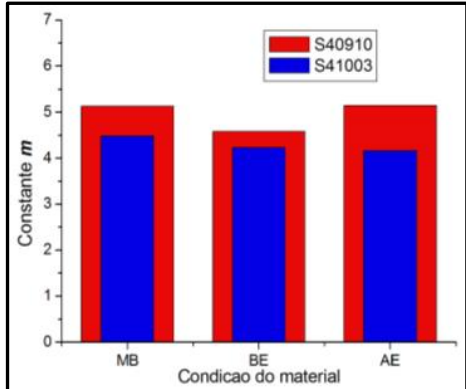

(b)

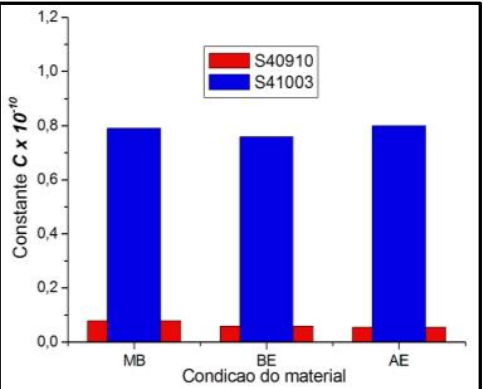

(c)

Figura 8. Efeito do aporte térmico de soldagem nos valores de (a) $\Delta K_{T H}$ e das constantes (b) $m$ e (c) $C$ da equação de Paris das juntas soldadas dos aços S40910 e S41003.

A Figura $9(a, b, c)$ apresenta microfratografias de corpos de prova ensaiados por fadiga do aço $\mathrm{S} 40910$ e da junta soldada correspondente, com os dois aportes térmicos. As fraturas estão relacionadas com a região I de crescimento de trinca. Pode-se observar a evolução do mecanismo de escorregamento de planos cristalográficos, com um crescimento de trinca na forma de "zig-zag", típico desta região de crescimento relativamente lento de trinca [23,24]. Considerando que a análise é feita com a mesma ampliação, percebe-se o efeito do aporte térmico no tamanho médio dos grãos cisalhados durante o crescimento da trinca de fadiga.

A Figura 10 mostra uma microfratografia típica da região II de crescimento de trinca por fadiga no aço S40910, com a formação de estrias. Este mecanismo ocorreu na região II em todos os corpos de prova ensaiados, independente do aço e da junta soldada.

Ainda sobre o aço S40910, é interessante apresentar a Figura 11, que mostra o efeito da presença de partículas de TiN no crescimento de trinca por fadiga. Nesta figura, pode-se observar que o mecanismo de formação de estrias está presente (parte superior da figura), mas subitamente a presença de TiN fragilizou a frente da trinca, mudando momentaneamente o mecanismo de falha para fratura frágil. Este fato aconteceu com frequência nas juntas soldadas do referido aço. Como consequência, a velocidade da trinca sofreu um aumento localizado significativo, conforme pode-se perceber na Figura 7(a) para as juntas soldadas BE e AE, próximo ao final da região II.

A Figura 12(a,b,c) apresenta microfratografias de corpos de prova ensaiados por fadiga do aço $\$ 41003$ e da junta soldada correspondente, com os dois aportes térmicos. As fraturas estão também relacionadas com a região I de crescimento de trinca (a região II sempre apresentou estrias de fadiga, conforme ilustrado na Figura 10). Neste caso, como o aço $\$ 41003$ não é estabilizado, formou-se martensita na ZTA, e a superfície de fratura dos corpos de prova apresentou duas regiões distintas e paralelas: de um lado a região correspondente à presença de martensita, do outro lado a região correspondente à presença de ferrita. Novamente percebe-se o efeito do aporte térmico no tamanho médio dos grãos das fases presentes durante o crescimento da trinca de fadiga. Mesmo com estas mudanças de mecanismos de fratura, a resistência à fadiga das juntas soldadas foi inalterada: o comportamento das juntas é semelhante a um arranjo tipo divisor de trinca de um material compósito, onde duas camadas distintas balanceiam o crescimento da frente da trinca [25].

\footnotetext{
* Contribuição técnica ao $69^{\circ}$ Congresso Anual da ABM - Internacional e ao 14ํㅡㄹ ENEMET - Encontro Nacional de Estudantes de Engenharia Metalúrgica, de Materiais e de Minas, 21 a 25 de julho de 2014, São Paulo, SP, Brasil.
} 


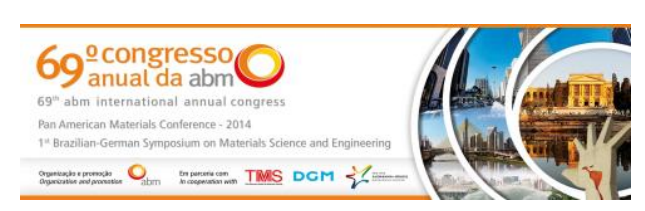

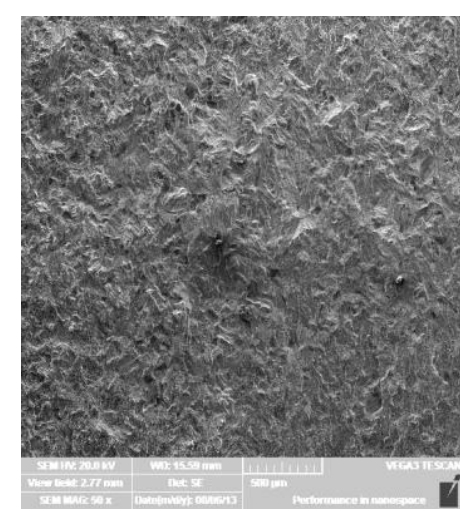

(a) MB

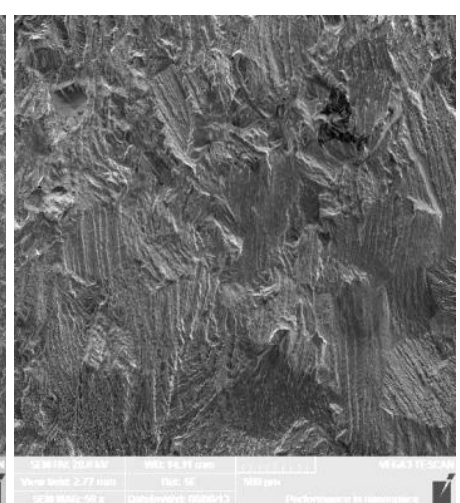

(b) $\mathrm{BE}$

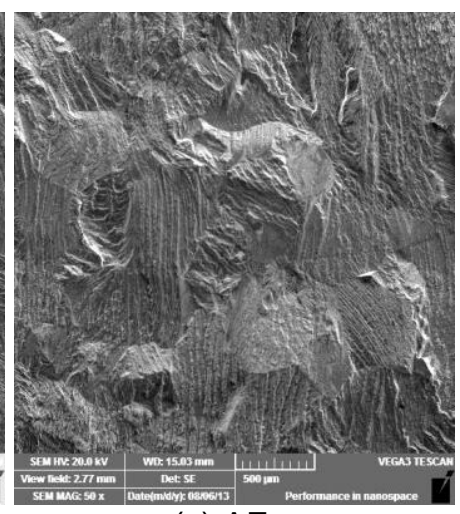

(c) $\mathrm{AE}$

Figura 9. Microfratografias de corpos de prova ensaiados por fadiga do aço $S 40910$ e juntas soldadas correspondentes, $d a / d N \approx 5 \times 10^{-7} \mathrm{~mm} /$ ciclo.

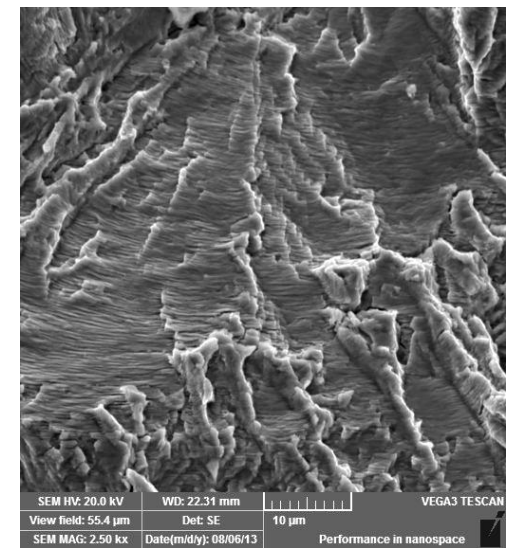

Figura 10. Estrias de fadiga em um corpo de prova do aço $S 40910, d a / d N \approx 5 \times 10^{-5} \mathrm{~mm} /$ ciclo.

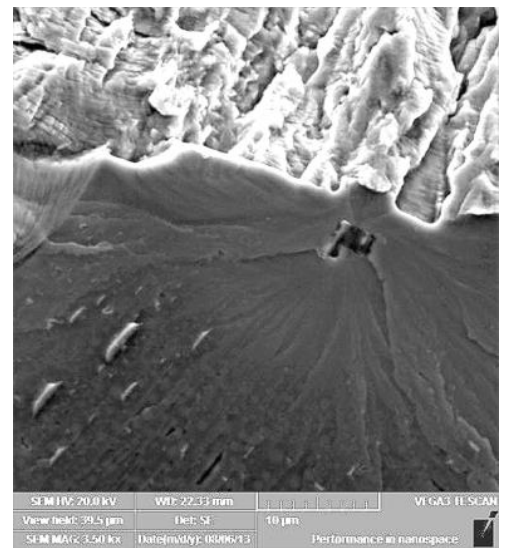

Figura 11. Mudança de mecanismo de crescimento de trinca em um corpo de prova

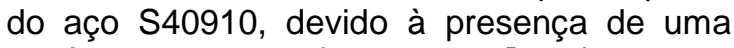
partícula de $\mathrm{TiN}, d a / d N \approx 5 \times 10^{-5} \mathrm{~mm} /$ ciclo.

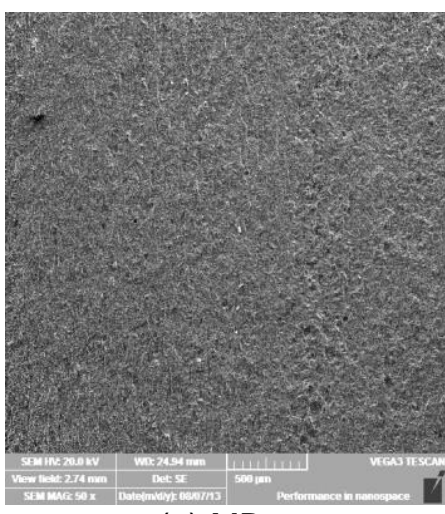

(a) MB

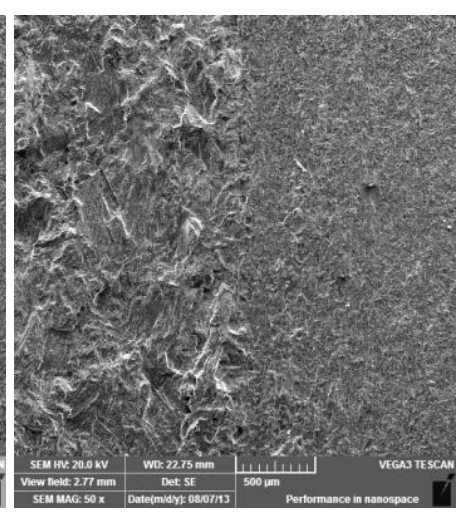

(b) $\mathrm{BE}$

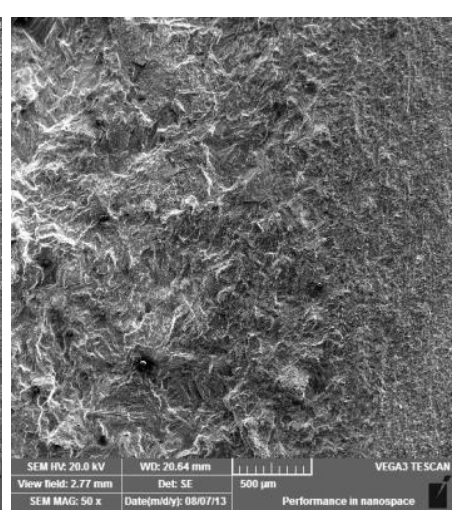

(c) $\mathrm{AE}$

Figura 12. Microfratografias de corpos de prova ensaiados por fadiga do aço $\$ 41003$ e juntas soldadas correspondentes, $d a / d N \approx 5 \times 10^{-7} \mathrm{~mm} /$ ciclo.

\section{CONCLUSÕES}

A partir dos resultados obtidos, as seguintes conclusões devem ser consideradas:

- O aço S40910 laminado a quente e estabilizado com titânio apresentou uma distribuição de grãos equiaxiais de ferrita na ZTA, com tamanho de grão médio igual a $45 \mu \mathrm{m}$. Por outro lado, o aço $\$ 41003$ laminado a quente e recozido apresentou uma distribuição de grãos alongados e heterogêneos de

\footnotetext{
* Contribuição técnica ao 69 Congresso Anual da ABM - Internacional e ao 14ํㅡㄹ ENEMET - Encontro Nacional de Estudantes de Engenharia Metalúrgica, de Materiais e de Minas, 21 a 25 de julho de 2014, São Paulo, SP, Brasil.
} 


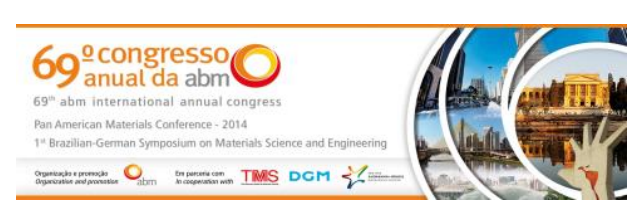

ferrita na ZTA, com tamanho de grão médio igual a $14 \mu \mathrm{m}$. Ambos os aços apresentaram uma fina distribuição de precipitados (carbonetos) dentro dos grãos e nos contornos de grãos, sendo que o aço S40910 ainda mostrou a presença de TiN em sua microestrutura.

- As soldas GMAW com único passe, realizadas com dois níveis de energia $(1,1 \mathrm{~kJ} / \mathrm{mm}$ e $1,8 \mathrm{~kJ} / \mathrm{mm})$ provocaram um crescimento de grão ferrítico na ZTA dos dois aços, com valores aproximadamente entre 200 e $300 \mu \mathrm{m}$. Na junta soldada do aço S41003 ocorreu a formação de martensita circundando os grãos de ferrita.

- O aço S40910 apresentou uma resistência ao crescimento de trinca por fadiga superior ao aço S41003 na região I da curva sigmoidal da/dN $x \Delta K$. Na região II da citada curva, o comportamento foi idêntico para os dois aços. Estes resultados estão relacionados com a operação do mecanismo de fechamento de trinca.

- As juntas soldadas relativas ao aço $\$ 40910$ tiveram um desempenho por fadiga inferior ao metal de base na região I do citado gráfico de fadiga, mas não sofreram influência da quantidade de aporte térmico. Por outro lado, para o aço S41003 não se verifica nenhum efeito significativo nas duas regiões das curvas sigmoidais, entre o metal de base e as juntas soldadas, qualquer que seja o aporte térmico.

\section{Agradecimento}

Os autores agradecem ao Eng. M.Sc. Alberto Hisashi Hibino, APERAM South America, pela doação de materiais (aços e juntas soldadas) envolvidos no presente trabalho.

\section{REFERÊNCIAS}

1 International Stainless Steel Forum. [acesso em mar. 2014]. Disponível em: www.worldstainless.org.

2 Infomine. [acesso em mar. 2014]. Disponível em: www.infomine.com.

3 Moll MA. Outlook for the Stainless Steel World Market. São Paulo: [s.n.]; 2008.

4 Peckner D, Bernstein IM. Handbook of Stainless Steels. p.5.02-5.25 McGraw-Hill Book Company; 1977.

5 Van Zwieten ACTM, Bulloch JH. Some Considerations on the Toughness Properties of Ferritic Stainless Steels - A Brief Review. Int. J. Pres. Ves. \& Piping; 1993.

6 Modenesi PJ. Soldabilidade dos Aços Inoxidáveis. São Paulo: SENAI; 2001.

7 Lula RA. Toughness of Ferritic Stainless Steels. California: ASTM; 1980.

8 Aperam South America: Produtos e Serviços - Aço Inox - Biblioteca Técnica. [acesso em mar. 2014]. Disponível em: www.aperam.com/brazil.

9 Meyer AM, Du Toit M. The Influence of Interstitial Diffusion Across the Fusion Line on the HAZ Microstructure and Properties in 12\% Chromium Type 1.4003 Steels. AWS. 2007 [acesso em out. 2009]. Disponivel em: www.aws.org/wj/supplement/Meyer12$01 . p d f$.

10 Oliveira TR, Faria RA. Metalurgia da soldagem dos aços inoxidáveis ferríticos. In: Seminário Inox 2000; 2000; São Paulo, Brasil. 2000. p.85-92.

11 Hibino AH, Modenesi PJ, Godefroid LB. Estudo de Tenacidade da Zona Termicamente Afetada dos Aços Inoxidáveis Ferríticos UNS S40910 e UNS S41003. In: XXXVII Congresso Nacional de Soldagem - CONSOLDA; 2011; Natal, Brasil. 2011.

\footnotetext{
* Contribuição técnica ao $69^{\circ}$ Congresso Anual da ABM - Internacional e ao 14ํㅡㄹ ENEMET - Encontro Nacional de Estudantes de Engenharia Metalúrgica, de Materiais e de Minas, 21 a 25 de julho de 2014, São Paulo, SP, Brasil.
} 


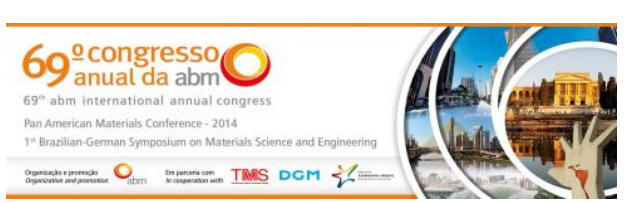

12 Hibino AH. Estudo de Tenacidade da Zona Termicamente Afetada dos Aços Inoxidáveis Ferríticos UNS S40910 e UNS S41003 [Dissertação de Mestrado]. Belo Horizonte: UFMG; 2011.

13 ASTM. Standard Specification for Chromium and Chromium-Nickel Stainless Steel Plate, Sheet, and Strip for Pressure Vessels and for General Applications A240. West Conshohocken; 2010.

14 ASTM. E647-08: Standard Test Method for Measurement of Fatigue Crack Growth Rates. Annual Book of ASTM Standards; 2001

15 Al-Rubaie KS, Barroso EKL, Godefroid LB. Fatigue crack growth analysis of pre-strained 7475-T7351 aluminum alloy. International Journal of Fatigue. 2006;28:934-942.

16 Al-Rubaie KS, Barroso EKL, Godefroid LB. Statistical modeling of fatigue crack growth rate in pre-strained 7475-T7351 aluminum alloy. Materials Science \& Engineering A. 2008;486:585-595.

17 Lippold JC, Kotecki DJ. Welding Metallurgy and Weldability of Stainless Steels. New Jersey: Wiley-Interscience; 2005.

18 SILVA JMFD. Melhoria da Lingotabilidade do Aço Inoxidável Ferrítico AISI 409 na ArcelorMittal Inox Brasil [Dissertação de Mestrado]. Belo Horizonte: UFMG; 2009.

19 Brandi SD, Faria RA. Relatório Técnico - Acesita S/A; 1999.

20 Du Toit M, Van Rooyen GT, Smith D. Heat-Affected Zone Sensitization and Stress Corrosion Cracking in 12\% Chromium Type 1.4003 Ferritic Stainless Steel. Corrosion. 2007;63(5).

21 Tanaka K, Akiniwa Y, Yamashita M. Fatigue Growth Threshold of Small Cracks. International Journal of Fatigue. 1981;17:519-533.

22 Landgraf RW. Fatigue Resistance and Microstructure of Ferrous Alloys. Metals Handbook. Vol. 19; 1998.

23 Al-Rubaie KS, Godefroid LB, Lopes JAM. Statistical Modeling of Fatigue Crack Growth Rate in Inconel Alloy 600. International Journal of Fatigue. 2007;29:931-940.

24 Godefroid LB, Andrade MS, Machado FA, Horta WS. Effect of Prestrain and Bake Hardening Heat Treatment on Fracture Toughness and Fatigue Crack Growth Resistance of Two Dual-Phase Steels. In: Materials Science \& Technology 2011 Conference \& Exibition; 2011; USA. ASM/AIST; 2011.

25 Godefroid LB, Chawla KK. Comportamento em Fadiga de Conjugados Laminados de Al1100/Al-2024. In: Anais do 3ํㅡ Colóquio Latino-Americano de Fadiga e de Fratura dos Materiais, ALAMET; 1988; Rio de Janeiro, Brasil. 1988; v.2. p.900-911.

\footnotetext{
* Contribuição técnica ao 69ำ Congresso Anual da ABM - Internacional e ao 14ํㅡㄹ ENEMET - Encontro Nacional de Estudantes de Engenharia Metalúrgica, de Materiais e de Minas, 21 a 25 de julho de 2014, São Paulo, SP, Brasil.
} 